\title{
The Effect of Mental Training on Motor Performance of Tennis and Field Hockey Strokes in Novice Players
}

\author{
Khaled Hegazy ${ }^{1,2}$, Amin Mohamed Sherif ${ }^{2}$, Samir Shapan Houta ${ }^{2}$ \\ ${ }^{1}$ Department of Sports and Sports Science, Karlsruhe Institute of Technology, Karlsruhe, Germany \\ ${ }^{2}$ Faculty of Physical Education for Men, Alexandria University, Alexandria, Egypt \\ Email: khaled.hegazy@kit.edu
}

Received 12 February 2015; accepted 9 April 2015; published 14 April 2015

Copyright (C) 2015 by authors and Scientific Research Publishing Inc.

This work is licensed under the Creative Commons Attribution International License (CC BY).

http://creativecommons.org/licenses/by/4.0/

(c) (i) Open Access

\section{Abstract}

The aim of this study was to investigate whether the mental training of motor performance can be useful or not in learning tennis and field hockey strokes (forehand, backhand; push pass, hit) Twenty four male tennis-field hockey novice players participated in the study and were divided into experimental group $(\mathrm{N}=12)$ and group for the scientific treatment of the tests $(\mathrm{N}=12)$. Subjects were recruited from Faculty of Physical Education for Men, Alexandria University, Egypt, with ages between 19 to 20 years old. The experimental group attended 16 sessions ( 8 for tennis, 8 for field hockey) over six weeks (40 minutes each) and used mental training exercises (relaxation, visualization and concentration-attention control) pertinent to the forehand, backhand in tennis and push pass, hit in field hockey. Two waves of measurements were conducted (before and after the completion of the intervention) with the use of motor assessment tests related to the sport of tennis and field hockey. Each student was evaluated regarding to his technique of forehand, backhand in tennis and push pass, hit in field hockey in order to examine the effectiveness of mental training. Questionnaires were also used to measure visualization and concentration-attention control. The results showed a highly significant improvement in learning forehand, backhand in tennis and push pass in field hockey. However, no statistical difference was found for the performance of the hit stroke in field hockey. In addition, the findings showed also a significant difference between the initial and the final measurement regarding to the ability of concentration and visualization by using questionnaires. The results revealed a value of 0.780 which indicates a good reliability of the tool. As a conclusion, a combination of mental and practical training promises the greatest improvement in performance and learning, because it involves all senses.

\section{Keywords}

Tennis, Field Hockey, Mental Training, Visualization, Mental Imagery 


\section{Introduction}

Numerous papers have been published in recent years related to the importance of mental training in sport (Jekauc \& Woll, 2006; Weinberg, 2008; Thelwell et al., 2006; Taylor \& Shaw, 2002; Coelho et al., 2008; Mayer \& Hermann, 2009; Hegazy, 2012; Vealey \& Greenleaf, 2006). Mental training techniques have been largely used by psychologists, coaches and athletes as a tool for improving learning and performance in sports (Hall \& Fishburne, 2010).

Sport imagery can be defined as using all senses to re-create or create a sport experience in the mind with the goal of enhancing sport performance during training and competition (Morris et al., 2005; Taylor \& Wilson, 2005; Weinberg \& Gould, 2014). Therefore, to use imagery effectively Gill \& Williams (2008) have suggested some strategies: Practice imagery regularly, and develop it through training, and continued practice. Imagery is not a substitute for physical practice, but a skill to enhance practice and performance.

Tennis and field hockey are complex and dynamic games in which players repeatedly make decisions regarding stroke technique selection (e.g. A good shooter needs to understand which technique to use.) (MartinezGallego et al., 2013; Anders \& Myers, 2008). The basis of tennis play is technique. Without a well mastered technique, all efforts of a coach in furthering the development of the player are questionable. The greatest danger for a beginner is learning a stroke in an incorrect way. Once the body learns a movement pattern it is hard to unlearn it. Erasing an existing muscle memory and replacing it with a new one can be a frustrating and painstaking process (Hegazy, 2012).

The quality of technique has a decisive influence on performance in tennis, as technique is the signature of the player by which he transfers all his conditioning, mental abilities and tactics to the ball, and, through it, on to the opponent. This is all the more reason why a great deal of attention should to be given to its optimal development (Schönborn, 2000: p. 13).

Furthermore, an excellent technique and well-defined coordination abilities allow speed to develop on its own. Seen in this way, speed, co-ordination ability and technique work as a "unit” in tennis (Grosser \& Schönborn, 2007).

When learning a new stroke or trying to refine a new technique on a particular stroke, it is important to focus on body mechanics and the feel of the movement (Renström, 2002).

Before diagnosing any stroke a coach must acknowledge that flaws in technique may not be mechanically based. They may be caused by psychological factors (e.g. stress, anxiety), poor tactical decisions (e.g. position on court does not permit the selected shot to be hit effectively) or a lack of fitness (e.g., poor foot movement in positioning for the stroke) (Elliot \& Alderson, 2003).

Forehand and backhand in tennis are the most common use in the field, similarly push pass and hit in field hockey, players must be able to handle the ball, and they have to handle it under the pressures of time, limited space, physical exhaustion, and dogged challenges from opponents. Every time the hockey ball moves, the situation changes and the decision-making abilities of players are tested. The individual's ability to execute decisions that are essential to team play must be developed (Anders \& Myers, 2008). To our knowledge, there is no study that compares the effect of mental training on both sport strokes so far, especially, the using of relaxation, visualization and concentration to improve the learning for novice players.

The purpose of the study was to examine the effect of mental training on learning ground strokes in tennis and field hockey.

\section{Method and Procedure}

\subsection{Participants}

24 university students participated in the study and were divided into 12 students for the experimental group and 12 students for the scientific treatment of the tests, recruited from the 3rd grade of the Faculty of Physical Education for Men, Alexandria University, Egypt. Subjects were novice in tennis and field hockey with ages between 19 - 20 years old, which would respond better to the demands of the questionnaire used.

\subsection{Experimental Design}

The study was carried out on the basis of teaching an interventional sport education program of tennis and field hockey. The program was planned and implemented during the university year 2013-2014, began on March $10^{\text {th }}$ 
and was completed on April $14^{\text {th }}$, the duration was approximately six weeks. One experimental group received pre-test-mental training program-post test. Students were taught tennis and field hockey strokes based on mental training, specifically relaxation, visualization and concentration-attention control. The students watched photos and video clips of top level tennis and field hockey players in slow motion in order to follow the whole path technique for each stroke. 16 sessions (8 for tennis, 8 for field hockey) were designed according to the mental training in the available time settled by the university board. The frequency of the sessions was three times a week divided into one session for tennis followed by other one for field hockey, alternately with each training session lasting for 40 minutes as shown in the following Table 1.

\subsection{Measurement Process}

Measurements were conducted with the use of motor evaluation tests and questionnaires, once before the implementation of the program and once after the completion of the program. After the end of the practical part, the process of the questionnaire would begin. The students were initially informed about the process and special emphasis was placed on the anonymity of the questionnaire. In addition, they were assured about the confidentiality of their answers and the fact that these would be used exclusively within the framework of the specific study. Then the questionnaire was delivered. Before having them fill in the questionnaire, they were provided with the essential standardized instructions and then they had time at their disposal to fill it in a calm, free and independent way.

\subsection{Instruments}

\subsubsection{Motor Test}

The test-game with strokes against the instructor in the tennis field (performance technique in tennis) was used to examine the effectiveness of the mental training in learning tennis strokes (Forehand and backhand). Participants were instructed to hit the balls against the instructor and then come back with one bounce and be stroked again, as many times as possible in the tennis field. The strokes were evaluated in terms of five steps (ready position-preparation-swing-impact-follow-up) by two tennis experts. Each participant was evaluated regarding to his technique of forehand and backhand using a scale from 1 to 5 degrees (Hegazy \& Sherif, 2013).

The test-game with strokes in the hockey field (performance technique in hockey) was used to examine the effectiveness of the mental training in learning field hockey strokes (push pass and hit). Participants were also instructed to push and hit the balls, as many times as possible in the hockey field. The push pass was evaluated in terms of four steps (ready position-preparation-push-follow-up), the hit was evaluated in terms of five steps (ready position-backswing-front swing-impact-follow-up) by two hockey experts. Each participant was evaluated regarding to his technique of both strokes, using a scale from 1 to 4 degrees for push, a scale from 1 to 5 for hit.

Table 1. Time distribution of the units and components of the mental training program for tennis and field hockey.

\begin{tabular}{|c|c|c|c|c|c|c|c|c|c|}
\hline \multirow[t]{2}{*}{$\mathrm{S}$} & \multirow{2}{*}{ Week } & \multirow{2}{*}{$\begin{array}{l}\text { Unit components } \\
\text { (Tennis and } \\
\text { Hockey) }\end{array}$} & \multirow{2}{*}{$\begin{array}{l}\text { Time of each } \\
\text { component within } \\
\text { the units }\end{array}$} & \multicolumn{2}{|c|}{$\begin{array}{l}\text { Number of } \\
\text { the units }\end{array}$} & \multicolumn{2}{|c|}{$\begin{array}{l}\text { Time of } \\
\text { the unit }\end{array}$} & \multicolumn{2}{|c|}{$\begin{array}{l}\text { Total time } \\
\text { of the unit }\end{array}$} \\
\hline & & & & Tennis & Hockey & Tennis & Hockey & Tennis & Hockey \\
\hline \multirow{3}{*}{1} & \multirow{3}{*}{$\begin{array}{l}\text { First and } \\
\text { Second } \\
10 / 3 \text { to } \\
21 / 3 / 2014\end{array}$} & Relaxation & 15 & & & & & & \\
\hline & & Visualization & 10 & 2 & 3 & $40 \mathrm{~m}$ & $40 \mathrm{~m}$ & $80 \mathrm{~m}$ & $120 \mathrm{~m}$ \\
\hline & & Concentration & 15 & & & & & & \\
\hline \multirow{3}{*}{2} & \multirow{3}{*}{$\begin{array}{l}\text { Third and } \\
\text { Fourth } \\
22 / 3 \text { to } \\
4 / 4 / 2014\end{array}$} & Relaxation & 15 & & & & & & \\
\hline & & Visualization & 10 & 3 & 3 & $40 \mathrm{~m}$ & $40 \mathrm{~m}$ & $120 \mathrm{~m}$ & $120 \mathrm{~m}$ \\
\hline & & Concentration & 15 & & & & & & \\
\hline \multirow{4}{*}{3} & \multirow{3}{*}{$\begin{array}{c}\text { Fifth and Sixth } \\
\text { 5/4 to } \\
14 / 4 / 2014\end{array}$} & Relaxation & 5 & & & & & & \\
\hline & & Visualization & 10 & 3 & 2 & $40 \mathrm{~m}$ & $40 \mathrm{~m}$ & $120 \mathrm{~m}$ & $80 \mathrm{~m}$ \\
\hline & & Concentration & 25 & & & & & & \\
\hline & Total & & & 8 & 8 & & & $320 \mathrm{~m}$ & $320 \mathrm{~m}$ \\
\hline
\end{tabular}




\subsubsection{Questionnaires}

1) Visualization test. Martens scale (1982) translated into Arabic by Shamon (1999), was used to measure the level of using the student's senses during the visualization and was modified by the researchers to suite the intervention. Students answered according to a scale of semantics differentiation (5-grade scale).

2) Concentration and attention control test. The students were asked to watch photos and video clips of top level tennis and field hockey players in slow motion in order to follow the whole path technique for each stroke. 3 questions were formulated in order to test the ability of concentration, which had to be answered in no more than 30 seconds, one mark was given for each correct answer.

\section{Results}

\subsection{Reliability}

The alpha coefficient was estimated for the examination of the internal consistency. The results revealed a value of 0.780 which indicates good reliability of the tool.

\subsection{Effectiveness of the Mental Training Technique}

The statistical package SPSS ver. 20 was used for the data analysis. Table $2 \&$ Table 3 show the means scores of forehand, backhand, push pass and hit strokes for the experimental group in tennis and field hockey before and after the intervention in order to study the effect of mental training on performance level, concentration ability and visualization, differences are observed between the initial and the final measurement. The scores are clearly better seen in the final measurement. Table 2 specifically shows a significant difference between the initial and the final measurement:

The forehand in tennis. Results showed a statistically significant difference between the initial $(M=1.92)$ and final measurement $(M=2.25), P=0.004$ for the performance, and between the initial $(M=2.08)$ and final measurement $(\mathrm{M}=2.83), P=0.021$ for the ability of concentration.

The backhand in tennis. Wilcoxon results revealed a statistically significant difference between the initial $(\mathrm{M}=$ 1.58) and final measurement ( $\mathrm{M}=3.33$ ), $P=0.007$ for the performance. In addition, statistically significant difference was found between the initial $(M=2.08)$ and final measurement $(M=2.75), P=0.033$ for the ability of concentration.

The push pass in field hockey. Results showed a statistically significant difference between the initial $(\mathrm{M}=$ 1.92) and final measurement ( $\mathrm{M}=3.25), P=0.003$ for the performance and between the initial $(\mathrm{M}=2.42)$ and

Table 2. Results of Wilcoxon for the performance and the concentration-attention control in tennis and field hockey.

\begin{tabular}{|c|c|c|c|c|c|c|c|c|c|c|c|c|}
\hline \multirow{3}{*}{ Items } & \multicolumn{6}{|c|}{ Performance } & \multicolumn{6}{|c|}{ Concentration and Attention Control } \\
\hline & \multicolumn{2}{|c|}{$\begin{array}{c}\text { Initial } \\
\text { Measurement }\end{array}$} & \multicolumn{2}{|c|}{$\begin{array}{c}\text { Final } \\
\text { Measurement }\end{array}$} & \multicolumn{2}{|l|}{ Wilcoxon } & \multicolumn{2}{|c|}{$\begin{array}{c}\text { Initial } \\
\text { Measurement }\end{array}$} & \multicolumn{2}{|c|}{$\begin{array}{c}\text { Final } \\
\text { Measurement }\end{array}$} & \multicolumn{2}{|l|}{ Wilcoxon } \\
\hline & M & SD & M & SD & $\mathrm{z}$ & $P$ & M & SD & M & SD & $\mathrm{z}$ & $P$ \\
\hline Forehand & 1.92 & 0.996 & 2.25 & 0.965 & 2.87 & 0.004 & 2.08 & 0.669 & 2.83 & 0.389 & 2.31 & 0.021 \\
\hline Backhand & 1.58 & 0.900 & 3.33 & 0.985 & 2.72 & 0.007 & 2.08 & 0.669 & 2.75 & 0.452 & 2.13 & 0.033 \\
\hline Push Pass & 1.92 & 0.289 & 3.25 & 0.754 & 3.02 & 0.003 & 2.42 & 0.515 & 3.00 & 0.000 & 2.65 & 0.008 \\
\hline Hit & 2.08 & 0.996 & 2.92 & 0.900 & 1.63 & 0.102 & 2.25 & 0.452 & 2.92 & 0.289 & 2.83 & 0.005 \\
\hline
\end{tabular}

Table 3. Results of Wicoxon for visualisation in tennis and field hockey.

\begin{tabular}{|c|c|c|c|c|c|c|}
\hline \multirow{3}{*}{ Items } & \multicolumn{6}{|c|}{ Visualization } \\
\hline & \multicolumn{2}{|c|}{ Initial Measurement } & \multicolumn{2}{|c|}{ Final Measurement } & \multicolumn{2}{|c|}{ Wilcoxon } \\
\hline & $\mathrm{M}$ & $\mathrm{SD}$ & $\mathrm{M}$ & $\mathrm{SD}$ & $\mathrm{z}$ & $P$ \\
\hline Tennis & 5.77 & 1.244 & 6.90 & 1.532 & 2.940 & 0.003 \\
\hline Hockey & 5.82 & 1.195 & 6.50 & 1.231 & 2.139 & 0.032 \\
\hline
\end{tabular}


final $(\mathrm{M}=3.00), P=0.008$ for the ability of concentration.

The hit in field hockey. No statistical difference was found between the initial and final measurement in terms of performance. However, there is a significant difference between the initial $(\mathrm{M}=2.25)$ and final $(\mathrm{M}=2.92), P=$ 0.005 for the ability of concentration.

Furthermore, Wilcoxon results revealed a statistically significant difference between the initial $(M=5.77)$ and the final measurement $(M=6.90), P=0.003$ in tennis regarding to the visualization test. Similarly, a statistical signify cant difference has been found between the initial $(M=5.82)$ and the final $(M=6.50), P=0.032$ in hockey, as it is clearly demonstrated in Table 3.

\section{Discussion}

The results revealed a significant difference between the initial and the final measurement regarding to the performance of the forehand, backhand in tennis and the push pass in field hockey. However, no statistical difference was found for the performance of the hit stroke in field hockey. In addition, the findings showed also a significant difference between the initial and the final measurement regarding to the ability of concentration and visualization by using questionnaires.

The results of the present study partially corroborates with those found in previous studies (Hall \& Fishburne, 2010; Mayer \& Herrman, 2009; Weinberg, 2008) which claim that mental training techniques have been largely used by psychologists, coaches and athletes as a tool for improving learning and performance in sports. In addition, imagery combined with relaxation is more effective than imagery alone (Gill \& Williams, 2008).

According to a survey by DeFrancesco \& Burke (1997), professional tennis players use strategies such as mental training, preparatory routines, relaxation training, goal setting, and systematically structured self-talk to aid in their performance. In the domain of motor skills and sport psychology, mental imagery has become an important component of a strategically organized learning experience.

Several studies have demonstrated that the use of mental imagery, combined with physical practice, contributes to the optimization of motor performance (Jones \& Stuth, 1997; Martin \& Hall, 1995; Overby et al., 1997-1998; Screws \& Surburg, 1997; Taktek, 2004; Wrisberg \& Anshel, 1989), but mental training is less effective than practical training, mental training is more effective than no training, mental training cannot replace physical training, but can considerably enhance it (Driskell et al., 1994; Mayer \& Herrman, 2009).

Moreover, imagery will only bring benefits to the athlete if he or she knows how, when and where to use it. Therefore, understanding the use of different models of imagery is necessary (Coelho et al., 2008). For examples, when Smith \& Holmes (2004) designed an imagery training program to improve golf putting, performance was enhanced more by mental practice using audiotapes and videotapes than by mental practice using written scripts that were read by the golfers. The interpretation of this finding was that imagery training using the audio- and videotapes engaged more functionally equivalent neural processes related to the actual execution of putting as compared to written scripts. Furthermore, researchers have shown that mental training is suitable for beginners as well as for performance optimization in intermediates and experts, also for children and youths for the optimization of precision and quality of movement (Eberspächer, 2004; Immenroth, 2003; Mayer \& Hermann, 2009).

Since the students were novice in tennis and field hockey, the hit stroke in field hockey needs from the player to control the power of the stick and conduct it to the ball by fast swing to hit the ball without any cutting for the movement and all this technique needs to be fast, which is not suitable for the novice students, that explains why there is no significant difference between the first and the last measurement for the hit stroke (Anders \& Myers, 2008).

The critical issues of the study are that the mental training exercises can be applied for more than eight sessions for each tennis and field hockey for a better learning of strokes performance. In addition, the sample size (24 students) is relatively small to detect more complex participation patterns. Possibly, a greater sample size would facilitate identification of more details.

\section{Conclusion}

Many more athletes and exercisers have begun using mental imagery not only to help their performances, but also to make their experiences in sport and exercise settings more enjoyable. Players can make use of mental training in a number of ways. Some can remember experiences and learn from them. Others can recall good ex- 
periences and best performances and practice recreating the feeling. A combination of mental and practical training promises the greatest improvement in performance and learning, because it involves all senses. Athletes can use imagery in many ways to improve both physical and psychological skills. One of the most common uses of imagery is mental practice for skill learning and practices a particular sport skill, in fact using imagery in this way allows athletes to learn and maintain technical skills for their sport, athletes also can use imagery to detect and correct errors in their routine, motion, or movement pattern.

\section{References}

Anders, E., \& Myers, S. (2008). Field Hockey: Steps to Success $\left(2^{\text {nd }}\right.$ ed.). USA: Human Kinetics.

Coelho, R. W., Oliveira, S., Elsangedy, H. M., Krinski, K., Colombo, H., Buzzachera, C. F., Campos, W., \& Silva, S. G. (2008). The Effect of Imagery in the Tennis Service Precision and Performance. Revista Brasileira de Cineantropometria \& Desempenho Humano, 10, 176-183.

DeFrancesco, C., \& Burke, K. L. (1997). Performance Enhancement Strategies Used in a Professional Tennis Tournament. International Journal of Sport Psychology, 28, 185-195.

Driskell, J., Cooper, C., \& Moran, A. (1994). Does Mental Practice Enhance Performance? Journal of Applied Psychology, 79, 481-492. http://dx.doi.org/10.1037/0021-9010.79.4.481

Eberspächer, H. (2004). Mentales Training-Ein Handbuch für Trainer und Sportler. Copress Verlag in der Stiebner.

Elliot, B., \& Alderson, J. (2003). Biomechanical Performance Models: The Basis for Stroke Analysis. In B. Elliot, M. Reid, \& M. Crespo (Eds.), Biomechanics of Advanced Tennis. Spain: The International Tennis Federation.

Gill, D. L., \& Williams, L. (2008). Psychological Dynamics of Sport and Exercise (3rd ed.). USA: Human Kinetics.

Grosser, M., Kraft, H., \& Schönborn, R. (2007). Speed Training for Tennis (2nd ed.). Oxford: Meyer \& Meyer Sport.

Hall, N., \& Fishburne, G. (2010). Mental Imagery Research in Physical Education. Journal of Imagery Research in Sport and Physical Activity, 5, 1-17. http://dx.doi.org/10.2202/1932-0191.1045

Hegazy, K. (2012). The Effect of Mental Training on Precision Tasks in Tennis and Soccer. A Study on Educational Technology. Ph.D. Thesis, Konstanz: University of Konstanz.

Hegazy, K., \& Sherif, A. (2013). The Impact of Mental Practices of Motor Performance of Tennis Skills in Young Boys and Girls. Proceedings of the 11th International Scientific Conferences for Physical Education and Movement Sciences, Sport in Theory and Practice, Alexandria, 58-63.

Immenroth, M., Haasis, M., Mayer, J., \& Eberspächer, H. (2003). Mentales Training im Lebenslauf (I)—Kinder. In J. Munzert, S. Künzell, H. Maurer, M. Reiser, N. Schott, \& K. Zentgraft (Eds.), Psychomotorische Entwicklung-Sport und Bewegung im Lebenslauf (p. 65). Giessen: Jahrestagung der Arbeitsgemeinschaft für Sportpsychologie.

Jekauc, D., \& Woll, A. (2006). Effektivität einer Ergebnisfokussierten Mentaltechnik. In M. Raab, A. Arnold, K. Gärtner, J. Köppen, C. Lempertz, N. Tielemann, \& H. Castrow (Hrsg.), Zukunft der Sportspiele: Fördern, fordern, forschen (pp. 108-110). Flensburg: Flensburg University Press.

Jones, L., \& Stuth, G. (1997). The Uses of Mental Imagery in Athletics: An Overview. Applied and Preventive Psychology, 6 , 101-115. http://dx.doi.org/10.1016/S0962-1849(05)80016-2

Martens, R. (1982). Imagery in Sport. Proceedings of the Medical and Scientific Aspects of Elitism in Sport Conference, Brisbane.

Martin, K. A., \& Hall, C. R. (1995). Using Mental Imagery to Enhance Intrinsic Motivation. Journal of Sport and Exercise Psychology, 17, 54-69.

Martinez-Gallego, R., Guzman, J. F., James, N., Pers, J., Ramon-Llin, J., \& Vuckovic, G. (2013). Movement Characteristics of Elite Tennis Players on Hard Court with Respect to the Direction of Ground Strokes. Journal of Sport Science and Medicine, 12, 275-281.

Mayer, J., \& Hermann, H. D. (2009). Mentales Training: Grundlagen und Anwendung in Sport, Rehabilitation, Arbeit und Wirtschaft. Heidelberg: Springer Medizin Verlag.

Morris, T., Spittle, M., \& Watt, A. P. (2005). Imagery in Sport. Champaign, IL: Human Kinetics.

Overby, L. Y., Hall, C., \& Haslam, I. (1997-1998). A Comparison of Imagery Used by Dance Teachers, Figure Skating Coaches, and Soccer Coaches. Imagination, Cognition and Personality, 17, 323-337. http://dx.doi.org/10.2190/W56X-HNDF-7YHL-G0TB

Renström, A. F. H. (2002). Elbow Injuries in Tennis. In A. F. H. Renström (Ed.), Handbook of Sports Medicine and Science: Tennis (p. 233). Oxford: Blackwell Science Ltd. http://dx.doi.org/10.1002/9780470698778

Schönborn, R. (2000). Advanced Techniques for Competitive Tennis (2nd ed.). Aachen: Meyer \& Meyer Sport. 
Screws, D. P., \& Surburg, P. (1997). Motor Performance of Children with Mild Mental Disabilities after Using Mental Imagery. Adapted Physical Activity Quarterly, 14, 119-130.

Shamon, M. A. (1999). Sport Psychology and Psychological Measurement. Cairo: Center for Book Publication.

Smith, D., \& Holmes, P. (2004). The Effect of Imagery Modality on Golf Putting Performance. Journal of Sport and Exercise Psychology, 26, 385-395.

Taktek, K. (2004). The Effect of Mental Imagery on the Acquisition of Motor Skills and Performance. A Literature Review with Theoretical Implications. Journal of Mental Imagery, 28, 79-114.

Taylor, J. A., \& Shaw, D. F. (2002). The Effects of Outcome Imagery on Golf-Putting Performance. Journal of Sport Sciences, 20, 607-613. http://dx.doi.org/10.1080/026404102320183167

Taylor, J., \& Wilson, G. (2005). Applying Sport Psychology: Four Perspectives. Champaign, IL: Human Kinetics, 117-134. http://dx.doi.org/10.1016/j.psychsport.2004.11.001

Thelwell, R., Greenlees, I., \& Weston, N. (2006). Using Psychological Skills Training to Develop Soccer Performance. Journal of Applied Sport Psychology, 18, 254-270. http://dx.doi.org/10.1080/10413200600830323

Vealey, R. S., \& Greenleaf, C. (2006). Seeing Is Believing: Understanding and Using Imagery in Sports. In J. M. Williams (Ed.), Applied Sport Psychology: Personal Growth to Peak Performance (pp. 306-348). Boston, MA: McGraw-Hill.

Weinberg, R. (2008). Does Imagery Work? Effects on Performance and Mental Skills. Journal of Imagery Research in Sport and Physical Activity, 3. http://dx.doi.org/10.2202/1932-0191.1025

Weinberg, R. S., \& Gould, D. (2014). Foundations of Sport and Exercise Psychology (5th ed.). Champaign. IL: Human Kinetics.

Wrisberg, C. A., \& Anshel, M. H. (1989). The Effect of Cognitive Strategies on Free Throw Shooting Performance of Young Athletes. The Sport Psychologist, 3, 95-104. 